\title{
SOLUTION OF FUZZY CAUCHY PROBLEM USING VARIABLE STEP SIZE METHOD
}

\author{
*Kahlil, E.M. and **Fadhel, F.S. \\ * Department of Mathematics, College of Science, Al-Mustansiryiah University, \\ Baghdad, Iraq (E-mail: estaprak_math_fuzzy@yahoo.com). \\ ** Department of Mathematics, College of Science, Al-Nahrain University, Al-Jadria, \\ Baghdad, Iraq (E-mail:dr_fadhel67@yahoo.com).
}

\begin{abstract}
In this paper, we introduce fuzzy variable step size method for solving fuzzy Cauchy problem. The structure of this paper organizes as follows:

In section one some basic results on fuzzy numbers and definition of a fuzzy derivative. In section two we explain fuzzy variable step size method; the proposed algorithm is illustrated by solving example in section three.
\end{abstract}

\section{Keywords: Fuzzy differential equations, Cauchy problem, Variable step size method}

\section{1-Preliminaries:}

The concept of fuzzy derivative was first introduced by S.L.chang, L.A. zadeh in [1], it was followed up by D.Dubois, H. Prade in [2], who defined and used the extension principle, we applied variable step size method on other problem in Abda Al-qahar.S.W.[3], the existence and uniqueness theorem of fuzzy differential equation in Kahlil, E. M. [4], and another numerical method for solving fuzzy differential equations is introduced by $\mathrm{M}$. Ma, M. Friedman, A. Kandel [5] and S. Abbasbandy, T. Allah Viranloo [6].

A triangular fuzzy number $\mathrm{V}$ is defined by three numbers $a_{1}<a_{2}<a_{3}$ where the graph of $\mathrm{V}(\mathrm{x})$, the membership function of the fuzzy number $\mathrm{V}$, is a triangle with base on the interval $\left[a_{1}, a_{3}\right]$, and vertex at $x=a_{2}$. We specify $\mathrm{V}$ as $\left(\mathrm{a}_{1} / \mathrm{a}_{2} / \mathrm{a}_{3}\right)$, and it is obvious that:

$\mathrm{V}>0$ if $\mathrm{a}_{1}>0, \mathrm{~V} \geq 0$ if $\mathrm{a} 1 \geq 0, \mathrm{~V}<0$ if $\mathrm{a}_{3}<0$, and $\mathrm{V} \leq 0$ if $\mathrm{a}_{3} \leq 0$.

Let $\mathrm{E}$ be the set of all upper semi continuous normal convex fuzzy numbers with bounded r-level sets which means that if $\mathrm{V} \in \mathrm{E}$ then the $\mathrm{r}$-level set $[\mathrm{V}]_{\mathrm{r}}=\{\mathrm{s} / \mathrm{V}(\mathrm{s}) \geq \mathrm{r}$, $0<\mathrm{r} \leq 1]$, is a closed bounded interval which is denoted by $[\mathrm{V}]_{\mathrm{r}}=[\underline{\mathrm{V}}, \overline{\mathrm{V}}]$.

Let $\mathrm{I}$ be a real interval $[0,1]$. A mapping $\tilde{y}: \mathrm{I} \rightarrow \mathrm{E}$ is called a fuzzy process and its r-level set denoted by

$$
[\mathrm{y}]_{\mathrm{r}}=[\underline{y}(\mathrm{t} ; \mathrm{r}), \bar{y}(\mathrm{t} ; \mathrm{r})], \mathrm{t} \in \mathrm{I} ; \mathrm{r} \in(0,1] .
$$

The derivative $y^{\prime}(\mathrm{t})$ of a fuzzy process $y^{\prime}(\mathrm{t})$ is defined by:

$$
\left[y^{\prime}(\mathrm{t})\right]_{\mathrm{r}}=\left[\underline{y}^{\prime}(\mathrm{t} ; \mathrm{r}), \bar{y}^{\prime}(\mathrm{t} ; \mathrm{r})\right], \mathrm{t} \in \mathrm{I} ; \mathrm{r} \in(0,1] .
$$

Provided that this equation define a fuzzy number

Consider the fuzzy initial value problem:

$$
y^{\prime}(\mathrm{t})=\mathrm{f}(\mathrm{t}, y(\mathrm{t})), \mathrm{t} \in[0, \mathrm{~T}], y(0)=y_{0} \ldots .(1)
$$

Where $f$ is a continuous mapping from $R \times R$ into $\mathrm{R}$ and $y_{0} \in \mathrm{E}$ with r-level set:

$$
\left[y_{0}\right]_{\mathrm{r}}=[\underline{y}(0 ; \mathrm{r}), \bar{y}(0 ; \mathrm{r})], \mathrm{t} \in \mathrm{I} ; \mathrm{r} \in(0,1] .
$$

The extension principle of zadeh leads to the following definition of $\mathrm{f}(\mathrm{t}, y)$, when $y=y(\mathrm{t})$, is a fuzzy number given by:

$$
\mathrm{f}(\mathrm{t}, y)(\mathrm{s})=\sup \{y(\Omega) \backslash \mathrm{S}=\mathrm{f}(\mathrm{t}, \Omega), \mathrm{s} \in \mathrm{R}\} .
$$

It follows that

$$
[\mathrm{f}(\mathrm{t}, y)]_{\mathrm{r}}=[\mathrm{G}(\mathrm{t}, y ; \mathrm{r}), \mathrm{F}(\mathrm{t}, y ; \mathrm{r})], \mathrm{r} \in(0,1]
$$

Where,

$$
\begin{aligned}
& \mathrm{G}(\mathrm{t}, y ; \mathrm{r})=\min \left\{\mathrm{f}(\mathrm{t}, \mathrm{u}) \backslash \mathrm{u} \in[y]_{\mathrm{r}}\right\} \\
& \mathrm{F}(\mathrm{t}, y ; \mathrm{r})=\max \left\{\mathrm{f}(\mathrm{t}, \mathrm{u}) \backslash \mathrm{u} \in[y]_{\mathrm{r}}\right\}
\end{aligned}
$$

The mapping $\mathrm{f}(\mathrm{t}, y)$ is a fuzzy process and the derivative $\mathrm{f}^{\prime}(\mathrm{t}, y)$ is defined by

$$
\left[\mathrm{f}^{\prime}(\mathrm{t}, y)\right] \mathrm{r}=\left[\mathrm{G}^{\prime}(\mathrm{t}, y ; \mathrm{r}), \mathrm{F}^{\prime}(\mathrm{t}, y ; \mathrm{r})\right], \mathrm{r} \in(0,1]
$$

provided that this equation define a fuzzy number $\mathrm{f}^{\prime}(\mathrm{t}, y) \in \mathrm{E}$, where

$$
\begin{aligned}
& \mathrm{G}^{\prime}(\mathrm{t}, y ; \mathrm{r})=\min \left\{\mathrm{f}^{\prime}(\mathrm{t}, \mathrm{u}) \backslash \mathrm{u} \in[y]_{\mathrm{r}}\right\} \\
& \mathrm{F}^{\prime}(\mathrm{t}, y ; \mathrm{r})=\max \left\{\mathrm{f}^{\prime}(\mathrm{t}, \mathrm{u}) \backslash \mathrm{u} \in[y]_{\mathrm{r}}\right\}
\end{aligned}
$$


where $f$ satisfies lipschitz condition and system (1) satisfy the existence and uniqness theorem see Kahlil, E.M [4].

$$
\begin{aligned}
& \mathrm{G}(\mathrm{t}, y ; \mathrm{r})=\min \left\{\mathrm{f}(\mathrm{t}, \mathrm{u}) \backslash \mathrm{u} \in[y]_{\mathrm{r}}\right\} \\
& \mathrm{F}(\mathrm{t}, y ; \mathrm{r})=\max \left\{\mathrm{f}(\mathrm{t}, \mathrm{u}) \backslash \mathrm{u} \in[y]_{\mathrm{r}}\right\}
\end{aligned}
$$

\section{2-Variable Step Size Method:}

As it is known from the usual methods of numerical analysis, the step size is fixed during the fallowed approach of solution, but still there are some methods for reducing the

Local truncation error such as the variable step-size methods, [3].

In all fixed step-size methods the local truncation error will depends on $\mathrm{x}$ and on the numerical method used. But, in variable stepsize methods, we shall find an approximation to the solution at a point $\mathrm{x}_{\mathrm{f}}$ for the fuzzy initial value problem:

$$
y^{\prime}(\mathrm{x})=\mathrm{f}(\mathrm{x}, y(\mathrm{x})), \mathrm{x} \in\left[\mathrm{x}_{0}, \mathrm{~b}\right], y\left(\mathrm{x}_{0}\right)=y_{0}
$$

which are accurate to within a specified tolerance.

Therefore, it turns out the for reasonable effective estimates of the step-size required to attain a specified upper local truncation error and lower local truncation error (tolerance) $\varepsilon$, which can be found that uses only the order of the upper local truncation error and lower local truncation error, and do not require further knowledge about of the error term. The variable stepsize method which will be considered here is based upon comparison of the estimates of the one and two step methods of solution (this application to upper and lower $\alpha$-level values) of the value of $x$ at some time obtained by the numerical method with upper local truncation error term and lower local truncation error term. Those are of the form $\overline{\mathrm{c}} \mathrm{h}^{\mathrm{p}+1}$ and $\underline{\mathrm{c}} \mathrm{h}^{\mathrm{p}+1}$, where $\overline{\mathrm{c}}$ and $\underline{\mathrm{c}}$ are unknown constant and $p$ is the order of the method.

Suppose that we started with initial conditions $\overline{\mathrm{y}}_{\alpha_{0}}$ and $\underline{\mathrm{y}}_{\alpha_{0}}$, with step-size $\mathrm{h}_{0}$. Using the numerical method to find the solutions $\quad \overline{\mathrm{y}}_{\alpha}^{(1)}\left(\mathrm{x}_{0}+\mathrm{h}_{0}\right)$ and $\overline{\mathrm{y}}_{\alpha}^{(2)}\left(\mathrm{x}_{0}+\mathrm{h}_{0}\right)$ using the step-sizes $h_{0}$ and $\frac{h_{0}}{2}$, respectively.

That application to lower $\alpha$-level case in the same way, similarly, let:

$$
\overline{\mathrm{E}}_{\mathrm{est}}=\left|\overline{\mathrm{y}}_{\alpha}^{(1)}\left(\mathrm{x}_{0}+\mathrm{h}_{0}\right)-\overline{\mathrm{y}}_{\alpha}^{(2)}\left(\mathrm{x}_{0}+\mathrm{h}_{0}\right)\right|,
$$

Where $\mathrm{h}_{0}=\mathrm{h}_{\text {old. }}$.

If $\overline{\mathrm{E}}_{\mathrm{est}} \leq \varepsilon$, then the solution is achieved and we can consider $\overline{\mathrm{y}}_{\alpha}^{(2)}\left(\mathrm{x}_{0}+\mathrm{h}_{0}\right)$ as the solution at $\mathrm{x}_{0}+\mathrm{h}_{0}$. Otherwise if $\overline{\mathrm{E}}_{\mathrm{est}}>\varepsilon$, then we find another estimation of the step- size say $\mathrm{h}_{\text {new }}$ which will produce an $\overline{\mathrm{E}}_{\text {est }}<\varepsilon$. If this approximation is accepted, then the value of $h_{\text {new }}$ will be used as $h_{0}$ in the next step; if not, then it will be used as $\mathrm{h}_{0}$.

The above procedure is repeated similarly to the lower $\alpha$-level case.

A common question may arise, which is how to find $h_{\text {new? }}$ In this work, a new criterion has been developed for estimating the upper local truncation error and lower local truncation error, which control the stepsize. The problem of error estimation is one of the most important problems that faces the user while using variable step-size method. To understand the concept of the error especially, the upper local truncation error and lower local truncation error, Taylor series expansion can be used, such that,

$$
\begin{gathered}
\bar{y}_{\alpha}(\mathrm{x}+\mathrm{h})=\overline{\mathrm{y}}_{\alpha}+\mathrm{h} \overline{\mathrm{y}}_{\alpha}^{\prime}+\frac{\mathrm{h}^{2}}{2 !} \overline{\mathrm{y}}_{\alpha}^{\prime \prime}+\ldots+ \\
\frac{\mathrm{h}^{\mathrm{p}}}{\mathrm{p} !} \overline{\mathrm{y}}_{\alpha}^{(\mathrm{p})}+\frac{\mathrm{h}^{\mathrm{p}+1}}{(\mathrm{p}+1) !} \overline{\mathrm{y}}_{\alpha}^{(\mathrm{p}+1)}+\mathrm{O} \\
\left(\mathrm{h}^{\mathrm{p}+2}\right)
\end{gathered}
$$

Therefore, the upper local truncation error of order $\mathrm{p}$ must satisfy the condition:

$$
\left|\frac{\mathrm{h}^{\mathrm{p}+1}}{(\mathrm{p}+1) !} \overline{\mathrm{y}}_{\alpha}^{(\mathrm{p}+1)}\left(\mathrm{x}_{\mathrm{n}}\right)\right| \leq \varepsilon
$$

So, to estimate this quantity, we need to evaluate $\bar{y}_{\alpha}^{(p+1)}\left(x_{n}\right)$, which is a higher order derivative at the point $x_{n}$. Using the same analysis with the new step-size $\alpha$ Taylor series expansion may be written as: 


$$
\begin{aligned}
& \bar{y}_{\alpha}(\mathrm{x}+\alpha \mathrm{h})=\overline{\mathrm{y}}_{\alpha}+\alpha \mathrm{h} \overline{\mathrm{y}}_{\alpha}^{\prime}+\frac{(\alpha \mathrm{h})^{2}}{2 !} \overline{\mathrm{y}}_{\alpha}^{\prime \prime}+ \\
& \ldots+\frac{(\alpha \mathrm{h})^{\mathrm{p}}}{\mathrm{p} !} \overline{\mathrm{y}}_{\alpha}^{(\mathrm{p})}+\frac{(\alpha \mathrm{h})^{\mathrm{p}+1}}{(\mathrm{p}+1) !} \overline{\mathrm{y}}_{\alpha}^{(\mathrm{p}+1)}+ \\
& \mathrm{O}\left(\mathrm{h}^{\mathrm{p}+2}\right)
\end{aligned}
$$

This must satisfy the condition :

$$
\left|\frac{(\alpha h)^{p+1}}{(p+1) !} \bar{y}_{\alpha}^{(p+1)}\left(x_{n}\right)\right| \leq \varepsilon
$$

and upon using elementary manipulation, equation (2) may be rewritten as:

$$
\alpha \leq\left[\frac{\varepsilon}{\frac{\mathrm{h}^{\mathrm{p}+1}}{(\mathrm{p}+1) !} \overline{\mathrm{y}}_{\alpha}^{(\mathrm{p}+1)}\left(\mathrm{x}_{\mathrm{n}}\right)}\right]^{\frac{1}{\mathrm{p}+1}}
$$

Clearly, we can find $\alpha$ and get the new step-size such that $h_{\text {new }}=\alpha h_{\text {old }}$ i.e.

$$
\mathrm{h}_{\text {new }}=\mathrm{y}_{\mathrm{r}}^{\mathrm{k}} \mathrm{h}
$$

Similarly, we apply the above criteria to the lower $\alpha$-level case in the same approach.

\section{3-Numerical Results:}

To illustrate the accuracy of the above approach for solving fuzzy differential equation numerically, the following example is taken:

\section{Example:}

The above process will be illustrated by evaluating an approximation to $[\mathrm{y}(0.02)]_{\mathrm{r}}$ to within an accuracy of $\varepsilon=0.000001$, for the first order fuzzy differential equation:

$$
\begin{aligned}
& \mathrm{y}^{\prime}(\mathrm{x})=\mathrm{y}(\mathrm{x}), \mathrm{x} \in[0,1] \\
& \mathrm{y}(0)=(0.75+0.25 \mathrm{r}, 1.125-0.125 \mathrm{r}), \\
& \mathrm{r}=0.2
\end{aligned}
$$

Euler's method will be used and hence $\mathrm{p}=1$ in equation (3) in the upper and lower cases, with $\mathrm{h}_{0}=\mathrm{h}_{0}^{*}=0.02$. In order to solve this problem, we evaluate $\overline{\mathrm{y}}^{\prime \prime}(\mathrm{x})$ and $\mathrm{y}^{\prime \prime}(\mathrm{x})$, in upper and lower cases, which are respectively:

$$
\bar{y}^{\prime}(x)=\bar{y}(x), \bar{y}^{\prime \prime}(x)=\bar{y}^{\prime}(x)=\bar{y}(x)
$$

and also

$$
\underline{y}^{\prime}(x)=\underline{y}(x)
$$

\begin{tabular}{|c|c|c|c|c|}
\hline $\mathrm{x}_{\mathrm{i}}$ & $\bar{y}_{1}$ & $\bar{y}_{2}$ & $\overline{\mathrm{E}}_{\mathrm{est}}$ & $\mathrm{h}_{\text {old }}$ \\
\hline 0 & $1.12200 \mathrm{E}+00$ & - & - & - \\
\hline $1.33504 \mathrm{E}-03$ & $1.10146 \mathrm{E}+00$ & $1.10146 \mathrm{E}+00$ & $4.90148 \mathrm{E}-07$ & $1.33504 \mathrm{E}-03$ \\
\hline $1.34750 \mathrm{E}-03$ & $1.10295 \mathrm{E}+00$ & $1.10295 \mathrm{E}+00$ & $5.00000 \mathrm{E}-07$ & $1.34750 \mathrm{E}-03$ \\
\hline $2.69409 \mathrm{E}-03$ & $1.10443 \mathrm{E}+00$ & $1.10443 \mathrm{E}+00$ & $5.00000 \mathrm{E}-07$ & $1.34659 \mathrm{E}-03$ \\
\hline $4.03978 \mathrm{E}-03$ & $1.10592 \mathrm{E}+00$ & $1.10592 \mathrm{E}+00$ & $5.00001 \mathrm{E}-07$ & $1.34568 \mathrm{E}-03$ \\
\hline $5.38456 \mathrm{E}-03$ & $1.10741 \mathrm{E}+00$ & $1.10741 \mathrm{E}+00$ & $5.00000 \mathrm{E}-07$ & $1.34478 \mathrm{E}-03$ \\
\hline $6.72844 \mathrm{E}-03$ & $1.10890 \mathrm{E}+00$ & $1.10890 \mathrm{E}+00$ & 4.99998E-07 & $1.34387 \mathrm{E}-03$ \\
\hline $8.07141 \mathrm{E}-03$ & $1.11039 \mathrm{E}+00$ & $1.11039 \mathrm{E}+00$ & 4.99998E-07 & $1.34297 \mathrm{E}-03$ \\
\hline $9.413491-03$ & $1.11188 \mathrm{E}+00$ & $1.11188 \mathrm{E}+00$ & 4.99998E-07 & $1.34207 \mathrm{E}-03$ \\
\hline $1.07546 \mathrm{E}-02$ & $1.11337 \mathrm{E}+00$ & $1.113377 \mathrm{E}+00$ & $5.00000 \mathrm{E}-07$ & $1.34117 \mathrm{E}-03$ \\
\hline $1.20949 \mathrm{E}-02$ & $1.11486 \mathrm{E}+00$ & $1.114867 \mathrm{E}+00$ & $5.00000 \mathrm{E}-07$ & $1.34027 \mathrm{E}-03$ \\
\hline $1.34343 \mathrm{E}-02$ & $1.11636 \mathrm{E}+00$ & $1.116361 \mathrm{E}+00$ & $5.00000 \mathrm{E}-07$ & $1.33937 \mathrm{E}-03$ \\
\hline $1.47728 \mathrm{E}-02$ & $1.11785 \mathrm{E}+00$ & $1.117856 \mathrm{E}+00$ & $5.00000 \mathrm{E}-07$ & $1.33848 \mathrm{E}-03$ \\
\hline $1.61103 \mathrm{E}-02$ & $1.11939 \mathrm{E}+00$ & $1.119351 \mathrm{E}+00$ & $5.00000 \mathrm{E}-07$ & $1.33758 \mathrm{E}-03$ \\
\hline $1.74470 \mathrm{E}-02$ & $1.12084 \mathrm{E}+00$ & $1.120848 \mathrm{E}+00$ & $5.00001 \mathrm{E}-07$ & $1.33669 \mathrm{E}-03$ \\
\hline $1.87828 \mathrm{E}-02$ & $1.12234 \mathrm{E}+00$ & $1.12234 \mathrm{E}+00$ & $5.00001 \mathrm{E}-07$ & $1.33580 \mathrm{E}-03$ \\
\hline 0.02 & $1.12371 \mathrm{E}+00$ & $1.1237 \mathrm{E}+00$ & $4.157 \mathrm{E}-07$ & $1.21711 \mathrm{E}-03$ \\
\hline $\mathrm{x}_{\mathrm{i}}$ & $\underline{y}_{1}$ & $\underline{\mathrm{y}}_{2}$ & $\underline{\mathrm{E}}_{\mathrm{est}}$ & $\mathrm{h}_{\text {old }}$ \\
\hline 0 & $8.16000 \mathrm{E}-01$ & - & - & - \\
\hline $1.56548 \mathrm{E}-03$ & $8.01252 \mathrm{E}-01$ & $8.01252 \mathrm{E}-01$ & $4.90148 \mathrm{E}-07$ & $1.56548 \mathrm{E}-03$ \\
\hline $1.57990 \mathrm{E}-03$ & $8.02518 \mathrm{E}-01$ & 8.025192E-01 & $5.00000 \mathrm{E}-07$ & $1.579902 \mathrm{E}-03$ \\
\hline $3.15855 \mathrm{E}-03$ & 8.03786E-01 & $8.037866 \mathrm{E}-01$ & $5.00000 \mathrm{E}-07$ & $1.57865 \mathrm{E}-03$ \\
\hline 4.73596E-03 & $8.05054 \mathrm{E}-01$ & $8.05055 \mathrm{E}-01$ & $5.00000 \mathrm{E}-07$ & $1.57741 \mathrm{E}-03$ \\
\hline $6.31213 \mathrm{E}-03$ & 8.06323E-01 & $8.06324 \mathrm{E}-01$ & $5.00000 \mathrm{E}-07$ & $1.57616 \mathrm{E}-03$ \\
\hline $7.88705 \mathrm{E}-03$ & 8.07594E-01 & $8.07594 \mathrm{E}-01$ & 4.99999E-07 & $1.57492 \mathrm{E}-03$ \\
\hline $9.46074 \mathrm{E}-03$ & $8.08865 \mathrm{E}-01$ & $8.08866 \mathrm{E}-01$ & 4.99999E-07 & $1.57368 \mathrm{E}-03$ \\
\hline $1.10331 \mathrm{E}-02$ & $8.10138 \mathrm{E}-01$ & $8.10138 \mathrm{E}-01$ & $5.00000 \mathrm{E}-07$ & $1.572449 \mathrm{E}-03$ \\
\hline $1.26044 \mathrm{E}-02$ & $8.11411 \mathrm{E}-01$ & $8.11412 \mathrm{E}-01$ & $5.00000 \mathrm{E}-07$ & $1.571213 \mathrm{E}-03$ \\
\hline $1.41743 \mathrm{E}-02$ & $8.12685 \mathrm{E}-01$ & $8.12686 \mathrm{E}-01$ & $5.00001 \mathrm{E}-07$ & $1.56998 \mathrm{E}-03$ \\
\hline $1.57431 \mathrm{E}-02$ & $8.13961 \mathrm{E}-01$ & 8.13961E-01 & $5.00000 \mathrm{E}-07$ & $1.56874 \mathrm{E}-03$ \\
\hline $1.73106 \mathrm{E}-02$ & $8.15237 \mathrm{E}-01$ & $8.15238 \mathrm{E}-01$ & 4.99999E-07 & $1.567519 \mathrm{E}-03$ \\
\hline $1.8876 \mathrm{E}-02$ & $8.16515 \mathrm{E}-01$ & $8.16515 \mathrm{E}-01$ & $5.00000 \mathrm{E}-07$ & $1.56629 \mathrm{E}-03$ \\
\hline 0.02 & 8.17432E-01 & $8.174 \mathrm{E}-01$ & 4.794E-07 & $1.123049 \mathrm{E}-03$ \\
\hline
\end{tabular}

This implies $\underline{y}^{\prime \prime}(x)=\underline{y}^{\prime}(x)=\underline{y}(x)$

One can also notice that:

$$
\begin{aligned}
& \nabla^{\mathrm{k}} \overline{\mathrm{y}}\left(\mathrm{x}_{\mathrm{n}}, \mathrm{r}\right)=(-1)^{\mathrm{k}} \mathrm{h}^{\mathrm{k}} \overline{\mathrm{y}}^{(\mathrm{k})}\left(\mathrm{x}_{\mathrm{n}}, \mathrm{r}\right) \\
& \nabla^{\mathrm{k}} \underline{\mathrm{y}}\left(\mathrm{x}_{\mathrm{n}}, \mathrm{r}\right)=(-1)^{\mathrm{k}} \mathrm{h}^{\mathrm{k}} \underline{\mathrm{y}}^{(\mathrm{k})}\left(\mathrm{x}_{\mathrm{n}}, \mathrm{r}\right)
\end{aligned}
$$

This implies that:

$$
\begin{aligned}
& \mathrm{h}^{2} \overline{\mathrm{y}}^{\prime \prime}\left(\mathrm{x}_{\mathrm{n}}, \mathrm{r}\right)=\bar{y}_{\mathrm{n}}(\mathrm{r})-2 \bar{y}_{\mathrm{n}-1}(\mathrm{r})+\overline{\mathrm{y}}_{\mathrm{n}-2}(\mathrm{r}) \\
& \mathrm{h}^{* 2} \underline{\mathrm{y}}^{\prime \prime}\left(\mathrm{x}_{\mathrm{n}}, \mathrm{r}\right)=\underline{\mathrm{y}}_{\mathrm{n}}(\mathrm{r})-2 \underline{\mathrm{y}}_{\mathrm{n}-1}(\mathrm{r})+\underline{\mathrm{y}}_{\mathrm{n}-2}(\mathrm{r})
\end{aligned}
$$

The following results are obtained upon excuting computer programs

Table (1).

Numerical Results of Example. 


\section{4-Conclusion:}

- We note that the convergence accurate of this method depends on local truncation error and on value of tolerance.

- The longer of solution's steps in lower case always less than upper case.

- The accurate oh this method increased is most when the value of tolerance is smaller.

\section{5-References:}

1. S.W. Abdul-Qahar, "Numerical solution of delay differential equations using linear multistep methods", M.Sc.Thesis, Department of Mathematics and computer Applications, College of Science, Al-Nahrain University, 2004.

2. S. Abbasbandy and T. Allah Viranloo: "Numerical solution of fuzzy differential equation", Internet Reference (to Appear), 2002.

3. K. E. Atkinson, "An introduction to numerical analysis", John Wiley and Sons, Inc. 1989.

4. D. Dubois, H. Prade, "Towards fuzzy differential calculus: Part3, differenttiation, fuzzy sets and systems", 8, 1982, pp.225-233.

5. E. M. Kahlil, "The numerical solution of fuzzy differential equations using linear multistep methods", M. Sc. thesis, Department of Mathematics and Computer Applications, College of Science, Al-Nahrain University, 2005.

6. M. Ma., M. Friedman and A. Kandel, "Numerical solutions of fuzzy differential equations", Fuzzy Sets and Systems, 105, 1999, pp.133-138.

7. S.L. Chang, L.A. Zadeh, "On fuzzy mapping and control", IEEE Trans, Systems. Man Cybernet, 2, 1972, pp.30-34.

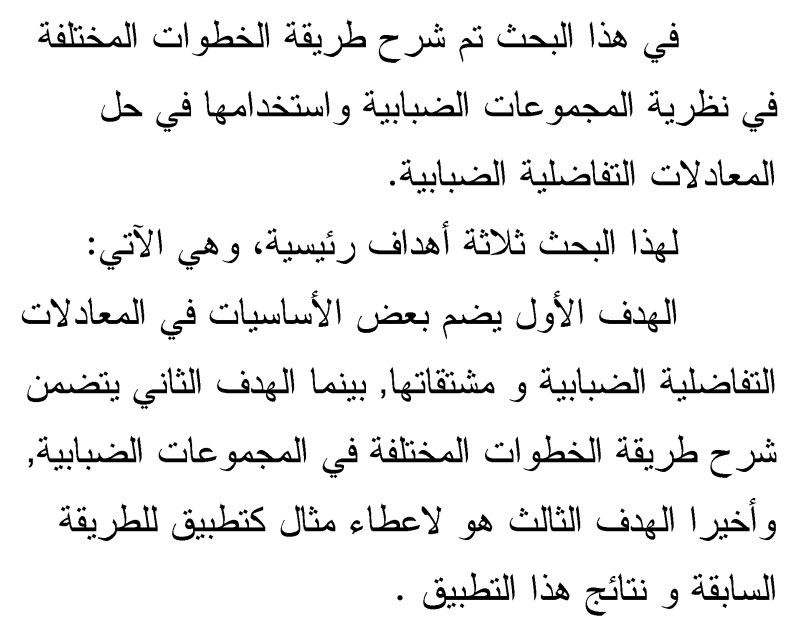

